Journal of Curriculum and Instruction (JoCl), November 2009, Volume 3, Number 2, (Barbara B. Howard,

Precious Guramatunhu-Mudiwa, and Stephen R. White)

\title{
Spiritual Intelligence and Transformational Leadership: A New Theoretical Framework
}

\author{
Barbara B. Howard \\ Precious Guramatunhu-Mudiwa \\ Stephen R. White \\ Appalachian State University
}

\begin{abstract}
The purpose of this paper is to establish a connection between spiritual intelligence and transformational leadership in an effort to encourage further debate about the legitimacy of spiritual intelligence in educational discourse. In this context we define spiritual intelligence as an interconnected configuration of affective orientations intimately linked to create meaning through connecting ideas, events, and persons rather than to a specific religious tradition or orientation. An exploration of the meaning of transformational leadership in education in $\mathrm{K}-12$ settings provides the basis for the development of a synthesis from a new perspective of two concepts that empower the dispositions of leadership impacting school culture.
\end{abstract}

The idea of spirituality is increasing in prominence among recent publications in educational psychology and theory (Dent, Higgins, \& Wharff, 2005; Edwards, 2003; Emmons, 1999, 2000a, 2000b; Fry, 2003; Fry \& Cohen, 2009; Fry \& Slocum, 2008; Gardner, 2000; Hyde, 2004; Mayer, 2000; Neiman, 2000; Rogers, 2003; Vaughan, 2002; Yang, 2006; Zohar, 2005). This reflects a shift toward the exploration of spiritual concerns previously submerged by the advent of scientific positivisms and the effort to reduce, if not eradicate, the role of spirituality in education (Bertrand, 2003; Sacks, 1999). This expository narrative addresses the integration of spirituality into educational transformational leadership theory and practice. As such, it lays the theoretical groundwork for further study.

\section{Definition of Spiritual Intelligence}

Spiritual intelligence in this context does not refer to a specific religious orientation. It is an interconnected configuration of affective orientations intimately linked to create meaning through connecting ideas, events, and persons (Dent, Higgins, \& Wharff, 2005; Fry, 2003). These connections result in both personal and organizational transformations. Spiritual intelligence is further defined as the ability to construct meaning through intuitively seeing interconnectedness between life-world experience and the inner spheres of the individual psyche (Rogers, 2003; Yang, 2006). Tisdell (2003) contends that spirituality is an important part of the human experience, which is fundamental to understanding how individuals construct meaningful knowledge. Tisdell asserts that spirituality has a deep cultural dimension that informs intellectual development. The process of meaning making is manifested in and mediated by cultural 
Journal of Curriculum and Instruction (JoCl), November 2009, Volume 3, Number 2, (Barbara B. Howard, Precious Guramatunhu-Mudiwa, and Stephen R. White)

context. For leaders to facilitate meaning making as a spiritual experience, they must make an empathetic linkage to organizational members' cultural grounding. In other words, the leader must be able to recognize as well as honor the cultural diversity of the organization in order to create an organizational culture of shared vision (Owens \& Valesky, 2007). Tisdell challenges us to construct an educational milieu that celebrates both the cultural differences and the commonalities of the human experience as a spiritual endeavor linked to the constructs of ethics and moral judgment. The challenge today is for the profession to recover its spiritual heritage (Parsons, Fenwick, Parson, English, \& Wells, 2002). The driving hypothesis of spiritual intelligence is that it is not dependent upon an organized religious orientation, but rather on the values and ethics of individuals as they contribute to organizational health and wellbeing.

\section{Review of Literature}

Emmons (1999) asserts that persons who demonstrate a capacity for heightened consciousness of transcendence possess spiritual intelligence. Spiritual intelligence empowers the individual to cope with and resolve life-world issues while demonstrating virtuous behavior such as humility, compassion, gratitude, and wisdom. Thus, he describes spiritual intelligence as a cognitive ability to envision unrealized possibilities and transcend ordinary consciousness through applying basic thought processes that have both temporal and existential meanings.

Biases against scientific study of constructs such as spirituality may be attributed to lack of precise definitions or a primary focus on associations rather than a focus on underlying mechanisms. A neuroscience perspective provides the necessary framework to encourage rigorous studies of such theoretical constructs by examining the neuropathology of the brain (Cacioppo, Hawkley, Rickett, \& Masi, 2005). Persinger (1996) and Ramachandran (1999) independently claim to have discovered the "God spot" within the brain. The "God spot" is an area in the brain that functions like a built-in spiritual center located within neural connections in the temporal lobes. Examinations of various brain scans, taken with positron emission topography, reveal that these neural areas light up whenever subjects are exposed to discussion of spiritual motifs. These scientists are very careful to point out that the "God spot" does not prove the existence of a divine being. Nevertheless, their findings strongly suggest that the brain is wired for cognitive constructs that produce meaning-making reflection. This suggests that humans are naturally predisposed to think in spiritual terms.

Singer and Gray (1995) discovered neural processes in the brain devoted to making interconnections that unify rational, emotional, and spiritual experiences. Prior to Singer and Gray's findings, the consensus in the scientific community was that the brain's organization was capable of producing only two neural processes: (a) neurological processes serially connecting neural tracts, allowing the brain to think logically and rationally and (b) neurological processes where thousands of neurons are interconnected in a chaotic mode of massively organized bundles resulting in affective thoughts. Observation of unifying neural oscillations means that a third kind of thinking exists - unitized thinking. The brain unitizes neurological organizations resulting in 
Journal of Curriculum and Instruction (JoCl), November 2009, Volume 3, Number 2, (Barbara B. Howard,

Precious Guramatunhu-Mudiwa, and Stephen R. White)

cognitive processes that seek the answer to meaningful questions (Singer, 1999; Singer \& Gray, 1995)

Deacon (1997) examined the evolution of symbolic imagination and its role in intellectual development. He proposed that the brain has the ability to construct symbolic imaginative processes resulting in deep reflective thinking about the meaning of life, experiences, and human existence. Zohar and Marshall (2001) defined spiritual intelligence as the intellectual ability to question why we are here and to be creative in our pursuit of answers. Thus, spiritual intelligence involves the cognitive processes resulting in both social modifications and consciousness transformations. Spiritual intelligence is rooted in the human need for understanding the world and our place in it.

Wolman (2001) argued that "understanding the context and meaning of our actions frees us to make conscious choices rather than enslaving us to respond reflexively to life's demands" (p. 3). Accordingly, developing spiritual intelligence empowers one to articulate ineffable moments that release the psyche's intrinsic spiritual energy.

\section{An Examination of Transformational Leadership}

Since its early days of development, transformational leadership theory has been a mainstay of organizational change based on its tenets of moral and ethical leadership behaviors that encourage the heart rather than control the behaviors (Bass, 1985, 1990, 1997; Burns, 1978; Kouzes \& Posner, 2002; Yukl, 1994). Much of the past research and literature on transformational leadership focused on the characteristics of the leaders themselves rather than on the interactions between the leader and his or her followers. These characteristics included charisma, creativity, consideration, sound moral judgment, and ethical decision-making (Friedman, 2004; Fry \& Cohen, 2009; Fry \& Slocum, 2008; Hyde, 2004; Rogers, 2003; Yang, 2006). Transformational leaders are those who can integrate the desires, beliefs, talents, and core beliefs into the work of an organization based on shared goals and visions (Friedman, 2004).

Morgan (1997) contended that transformational leadership establishes a shared vision, which results in followers exercising their capacity for creative expressions of self, thus exploring their work as a means of self-actualization. Morgan (1997) wrote:

[Transformational] leadership ultimately involves an ability to define the reality of others... He or she spends time listening, summarizing, integrating, and guiding what is being said, making key interventions and summoning images, ideas, and values that help those involved to make sense of the situation with which they are dealing (p. 184).

For any organization to be effective, leaders must be aware of this psyche force and energy to create a shared vision that speaks to the affective side of individuals. Senge, Scharmer, Jaworski, and Flowers (2004) collectively explored the notion of presence within the context of organizational systems' thinking and the nature of 
Journal of Curriculum and Instruction (JoCl), November 2009, Volume 3, Number 2, (Barbara B. Howard,

Precious Guramatunhu-Mudiwa, and Stephen R. White)

organizational and individual transformation. They suggest, "What's emerging is a new synthesis of science, spirituality, and transformational leadership as different facets of a single way of being" (p. 212).

Effective educational leaders focus on the development of the whole person in making meaningful connections between the social life-world within an organization and the psyche life-world within themselves by building an environment within which individuals and groups are encouraged to share visions, goals, and values (Thompson, 2004). Thompson asserted that "while leadership may not be framed in terms of morality and ethics, a sense of moral solidarity is at the heart of successful enterprise" (p. 28). In this sense the parallel development of the organization and its members ultimately brings them to the realization of their highest collective and individual potential. Transformational leaders honor spirituality as part of the organizational developmental process (Glazer, 1994; Miller, 2000; Miller \& Nakagawa, 2002; Sinetar, 2000).

\section{A Synthesis of Spiritual Intelligence and Transformational Leadership}

Spiritually grounded leaders exercising high levels of spiritual intelligence are animated thinkers who possess meaningful thought patterns, novel ideas, and rich imaginations because the soul is harmoniously integrated with the mind (Kessler, 2000; Moffett, 1994). The link between spiritual intelligence and transformational leadership can be strengthened through an examination of the following shared characteristics of charisma, consideration, and creativity.

\section{Provision of Guidance and Structure}

The school leader must become a servant leader who "initiates, provides the ideas and the structure, and takes the risk of failure along with the chance of success" (Greenleaf, 1977, p. 29). Re-tooling the existing culture of the $20^{\text {th }}$ century school requires even greater levels of spiritual intelligence as the leader transforms the organization into the expectations of the $21^{\text {st }}$ century global economy. Core beliefs of veteran educators must be challenged and transformed to create a new paradigm of teaching and learning. Denhardt (1981) described transformational leadership as a process of helping members individually, so that the collective becomes conscious of a new direction. Educational transformational leadership's development of organizational vision links to the individual's sense of spiritual drive and meaning construction.

The transformational leader plays a critical role in the development of an organizational vision by facilitating, coordinating, and supporting the access and process of meaning. This begins with self-introspection by asking fundamental questions about the richness of his or her own understanding (Bolman \& Deal, 2003; Vaughan, 2002). Furthermore, transformational leaders will ask themselves about their own fears, compulsions, biases, weaknesses, and general deficiencies. This reflective understanding of self provides a necessary filter enabling perceptions from multiple dimensions (Starratt, 1996). Once this filter is established, the transformational leader 
Journal of Curriculum and Instruction (JoCl), November 2009, Volume 3, Number 2, (Barbara B. Howard,

Precious Guramatunhu-Mudiwa, and Stephen R. White)

must develop a common understanding of the organizational vision drawn from individual understandings of disparate communities and groups within the school.

\section{Creation of Positive Working Environments}

Critical ingredients of transformational leadership are the relationships grounded in trust, authenticity, and genuine caring (Vaughan, 2002). Bolman and Deal (1995) viewed building positive work environments as a moral imperative while Sergiovannni (1992) defined leading from the heart as a sacred authority. Greenleaf (1977) defined this obligation as servant leadership. As such, the leader encourages people to express their ideas without fear of judgment (Fry, 2003). By sharing ideas, stakeholders can deconstruct their own tentative meanings to enrich, expand, and modify the development of a common organizational meaning in line with new expectations.

Fry (2003) and Vaughan (2002) emphasized inclusiveness as an important component of spiritual intelligence and leadership. We liken such collective organizational understanding to a tapestry where individual threads are interwoven to create art. When people look at the art, they are either inspired or uninspired. The inspired may ask questions to find deeper meaning and appreciation while the uninspired may move on and never ask questions. The collective understanding inspires people and becomes a source of energy if people appreciate the meaning of these standards and how they bring fulfillment to their work life. The leader must have the ability to read meaning from unspoken messages of stakeholders (Starratt, 1996).

Kouzes and Posner (2002) included celebration of accomplishment as one of the major commitments that must be made by the transformational leader. Such public displays and ceremonies reiterate key values while allowing leaders to develop those personal connections that support organizational growth. Recognizing and celebrating those accomplishments directly linked to shared goals promotes the self-actualization of individuals within the organization while furthering necessary change. Effective school leaders understand the important role a school's culture plays in the performance of its students by developing symbols reflective of the values and norms of the community. The transformational leader is able to enhance a school's culture by infusing the work of adults and children with passion, meaning, and purpose aligned with the shared goals of both the school and its community (North Carolina Department of Public Instruction, 2008).

Another concept tied to spiritual intelligence and transformational leadership is the judicious use of power. The new paradigm of school leaders requires administrators to redistribute and relinquish power so that others may enrich their experiences, seeking meaning and purpose for the overall good of the organization (North Carolina Department of Public Instruction, 2008). Leaders tend to gain more power when they distribute it within the organization (Bolman \& Deal, 1995; Sergiovanni, 2005).

Followers must be allowed to experiment and create their own solutions to organizational problems thus creating more buy-in (Kouzes \& Posner, 2002; 
Journal of Curriculum and Instruction (JoCl), November 2009, Volume 3, Number 2, (Barbara B. Howard, Precious Guramatunhu-Mudiwa, and Stephen R. White)

Sergiovanni, 1992). Teams feel connectedness and security through an open and supportive environment espoused by the leader (Bolman \& Deal, 2003; Fry, 2003; Vaughan, 2002). In effective schools, people talk about what they value and try to filter common values that bring meaning to activities about the goals. They openly question the worth of the activities. They develop a common understanding of values, norms, vision, direction, and frameworks necessary for the achievement of organizational goals. The transformational leader unleashes "the creativity, talent, and energy of a work force" (Fry, 2003, p. 709).

According to Sergiovanni (1992), the transformational leader may use leadership stages to move people to the ultimate goal of success. In the first stage, the leader arouses potential in people leading to higher levels of commitment and performance through a reliance on human relations and interpersonal skills. In other words, the focus is on empowerment with the leader seeking growth in others. In the second stage, the leader exercises moral leadership by taking it as an obligation to bring consciousness to the level of a shared covenant leading to purpose, meaning, and significance. The third stage is evident when followers internalize improvements that turn into routines. Without this level of transformational leadership built upon a strong foundation of spiritual intelligence, the school leader builds a culture of compliance rather than commitment.

Following Bolman and Deal's argument (2003), leaders need to create organizational soul and spirit. It is fair to assume that principals themselves do not know everything there is to know about the schools they lead. They would be advised to invite the participation and collaboration of stakeholders in order to bring a shared meaning

and purpose to create a learning environment that prepares students to thrive in the $21^{\text {st }}$ century global economy.

\section{The Capacity for Transcendence}

Fry (2003) called this capacity a calling or vocation, where members seek to make a difference through service and, in turn, derive meaning and purpose. Emmons (2000a) called it a heightened consciousness "denoted by going above and beyond the ordinary limits of physicality... and utilizing spiritual resources to solve problems" (p. 910). On the individual level, there are four domains that constitute the self: (a) physical, (b) mental, (c) emotional, and (d) spiritual (Fry, 2003; Moxley, 2000). Conger (1994) argued that transformational leadership exists in all dimensions of organizations and within every individual. In order to "see" beyond the existing organizational culture and practices we need a vision, a new way of seeing, that transcends the old view. This requires a basic spiritual condition which, if not tapped, will cause the organization to fail in the fulfillment of its mission and the fulfillment of the individuals comprising the organization (Moxley, 2000).

Leadership that is stalwart, virtuous, and nurturing is a spiritual experience (Conger, 1994; Vaughan, 2002). The bonds associated with the trust and faith that people have in one another is a central component of a compelling vision that taps the spirituality of people and organizations. The presence of the spiritual self is most 
Journal of Curriculum and Instruction (JoCl), November 2009, Volume 3, Number 2, (Barbara B. Howard,

Precious Guramatunhu-Mudiwa, and Stephen R. White)

notable when leaders seek to transform themselves and others to a higher order of thinking. Transformational leaders are those who inspire change rather than dictate it.

\section{A Practical Application of the Synthesis}

To demonstrate the relationship between spiritual intelligence and transformational leadership we examined it through the lens of one state's attempt to operationalize effective leadership, which provides a practical application of the proposed theoretical framework. The North Carolina State Board of Education (2006) recently adopted The Standards for School Executives. These standards are buttressed on competencies that include leadership in the following areas: (a) strategic, (b) instructional, (c) cultural, (d) human resources, (e) managerial, (f) external development, and (g) micro-political. Interwoven throughout the standards are the intentionally recurring themes of creating a strategic vision for learning and teaching, collaboration, teacher empowerment and leadership, community involvement and engagement, school safety, and organizational management and school improvement (North Carolina State Board of Education, 2006). These standards evolved from the work in leadership supported by the Wallace Foundation, the Mid-continental Regional Education Laboratory, and the Southern Regional Education Board among other research and professional organizations such as the National Council of Staff Development, the National Association of Secondary School Principals, and the Interstate School Leader Licensure Consortium (North Carolina Department of Public Instruction, 2008). The North Carolina State Board of Education based the constructs found in these standards on research-based practices of what effective school leaders actually do in a school. The model embraces the concept of distributive school leaders who facilitate the effective workings of their schools by ensuring that leadership occurs within the realm of each standard- either through their own actions or the actions of others (North Carolina State Board of Education, 2008). This conceptualization of leaders as transformational facilitators of learning organizations shifts dramatically from former paradigms of principals as managers of staffs, students, facilities, and programs. With this level of responsibility, principals must adopt those practices that include inspiring others to collaborate in realizing a shared vision for their school. Principals are expected to create schools in which large-scale and sustainable efforts for improvement become part of the school culture (North Carolina Department of Public Instruction, 2008).

The standards are intended to guide not only the licensure of new school administrators, but also their performance evaluation and ongoing professional development. These new standards present a shift from the principal as gatekeeper of the status quo to the school executive who adapts to the ever-changing educational landscape. The school executive is expected to guide the school as a successful $21^{\text {st }}$ century learning environment where students develop skills, dispositions, knowledge, and functional literacies required to compete in an interconnected world.

The scope and nature of these expectations emphasize the need for school executives to provide insightful transformational leadership with a high level of spiritual intelligence as defined above. According to Vaughan (2002), "refining any form of 
Journal of Curriculum and Instruction (JoCl), November 2009, Volume 3, Number 2, (Barbara B. Howard, Precious Guramatunhu-Mudiwa, and Stephen R. White)

intelligence requires training and discipline, and spiritual intelligence is no exception" (p. 20). The school executive must deliberately create a web of activities that moves the school progressively toward achieving organizational goals aligned with the emerging vision of $21^{\text {st }}$ century schools.

The transformational leader "engages the aspirations of followers, taps their motivations, energizes their mental and emotional resources, and involves them enthusiastically in the work to be done" (Owens \& Valesky, 2007, p. 282). For the North Carolina school executive, the challenge is to create collective meaning of the organizational goals of $21^{\text {st }}$ century learning. This requires that teachers and principals bring their core values to the table and connect to those perceived to move the school in the direction that fits this vision. Meaning-making is the hallmark of spiritual intelligence; for it to work, the leader must not neglect the spiritual dimension of the organization as a "powerful untapped source of energy and vitality" (Bolman \& Deal, 2003, p. 141). All stakeholders bring meaning through their individual perspectives on the workings of the organization from a rich tapestry of life experiences. A transformational leader must celebrate the diversity of these perspectives while creating a shared vision to develop a path of connectivity toward a common purpose (Starratt, 1996). The development of this level of connectivity requires both transformational leadership and spiritual intelligence.

\section{The Unresolved Debate}

While there has been a proliferation of literature on spiritual intelligence, we acknowledge that utilizing it raises many serious questions regarding limitations (Gardner, 2000; Mayer, 2000). The most obvious limitation is the stigma associated with the identification of spirituality as an intelligence. Gardner (2000) dismisses the idea of spiritual intelligence as a form of intelligence because of the lack of empirical evidence and that "intelligence is a biological potential to analyze kinds of information in certain ways" (p. 32). Gardner views intelligence as largely limited to cognition and computation, but not to feelings. Interestingly, James (as cited in Hyde, 2004) revealed that logical reason alone cannot explain the spiritual experience of individuals. Others embrace spiritual intelligence as the ultimate intelligence (Emmons, 1999, 2000a; Vaughan, 2002; Zohar, 2005; Zohar \& Marshall, 2001).

The lack of consensus on the value of spiritual intelligence in educational thought poses a difficult challenge for educators who subscribe to an interpretation of spirituality as being synonymous with specific theological ideologies (Rogers, 2003). Such thinking is deeply ingrained in our cultural consciousness and presents an obstacle that many may not be able to effectively overcome. Again, it must be emphasized that spiritual intelligence in this sense is not synonymous with organized religion. Incorporating the notion of spirituality into an organizational agenda is demanding for educators who are institutionally required to focus on objective content-based learning and conventional organizational and developmental processes. Educational leaders possessing positivistic and pragmatic dispositions will find it difficult to see the relevance of spiritual intelligence for reaching prescribed educational objectives. 
Journal of Curriculum and Instruction (JoCl), November 2009, Volume 3, Number 2, (Barbara B. Howard, Precious Guramatunhu-Mudiwa, and Stephen R. White)

Another challenge lies in the inherent tension between theoretical orientations toward education as a knowledge product endeavor versus learning as an intellectual growth process. Spiritual intelligence naturally falls into the latter theoretical mental model. The focus on spiritual intelligence can potentially create further anxiety for leaders who are already under the burden of proving academic performance and intellectual rigor. There is a possibility some leaders may become fearful that their spiritual intelligence measurement might impede their academic agenda or influence their followers' attitudes toward them. This is an issue that must be explored seriously to avoid creating a more convoluted educational context, which would ultimately be selfdefeating.

Equally important are the cultural, ethnic, and socioeconomic issues in an increasingly multicultural and socially stratified society. The confounding question is, can a highly subjective notion such as "spirituality" successfully and judiciously be measured against the organizational backdrop of members' racial, ethnic, gender, and cultural understandings of spirituality? We believe a simplistic view of spirituality in isolation of these issues raises serious ethical considerations regarding increasing bias in terms of supervision.

\section{Proposed Theoretical Motifs on Spiritual Intelligence}

We advance four theoretical motifs, which may hold several points of promise for transformational leadership behavior and organizational development in education. The first of these is that spiritual intelligence expands our understanding of organizational members by providing an objective pathway into the inner life so intimately related to organizational development (Dent, Higgins, \& Wharff, 2005; Fry, 2003; Vaughan, 2002; Yang, 2006; Zohar; 2005). Such insight can assist transformational leadership in integrating the rational and affective context of organizational development into holistic experiences. Secondly, spiritual intelligence provides a platform from which to build deeper relationships with organizational members (Fry, 2003; Fry \& Cohen, 2009; Fry \& Slocum, 2008; Hyde, 2004). Building relationships is the foundation of the link between objective organizational development and individual development. Thirdly, spiritual intelligence provides greater insight into augmenting instructional designs and practices by facilitating learner-centered contexts (Hyde, 2004; Neiman, 2000). This is important to developing increased participation in new designs by experienced educators, who may be resistant to changes in organizational vision. Perhaps most significant, the fourth theoretical motif is that spiritual intelligence awareness has the potential to increase the success of school leaders by providing important insight into their affective life-world that would enable them to transform schools. Expectations for effective leadership expand beyond managerial and instructional knowledge to tap into the realm of inspiration based on an affective cognition of individual needs, community culture, and shared values (Friedman, 2004; Kouzes \& Posner, 2002). For school leaders to be successful in transforming schools into high-performing learning communities, attention must be paid to the identification and development of the skills and dispositions associated with this level of inspirational leadership. 
Journal of Curriculum and Instruction (JoCl), November 2009, Volume 3, Number 2, (Barbara B. Howard,

Precious Guramatunhu-Mudiwa, and Stephen R. White)

\section{Conclusion}

Society is experiencing a resurgence of spirituality that is spilling over into educational thought (Dent, Higgins, \& Wharff, 2005; Emmons, 2000b; Fry, 2003; Fry \& Cohen, 2009; Fry \& Slocum, 2008; Gardner, 2000; Hyde, 2004; Mayer, 2000; Neiman, 2000; Rogers, 2003; Vaughan, 2002; Yang, 2006; Zohar; 2005). As a result, the proposal to explore spiritual intelligence as part of educational transformational leadership and organizational development is intriguing. Educational theorists and practitioners must expand their knowledge base regarding the linkage between spirituality, transformational leadership, and organizational development. Given the lack of consensus surrounding spiritual intelligence to qualify as intelligence and intellectual endeavor, we urge further research to resolve the debate. Discovering the depth of interrelationship and interconnectedness between spirituality and the art of transformational leadership vision and organizational dynamics may be the defining legacies of this generation of educational leaders.

\section{References}

Bass, B. M. (1985). Leadership and performance beyond expectation. New York: Free Press.

Bass, B. M. (1990). From transactional to transformational leadership: Learning to share the vision. Organizational Dynamics, 18(3), 19-31.

Bass, B. M. (1997). Transformational leadership: Industrial, military, and educational impact. Mahweh, NJ: Lawrence Erlbaum.

Bertrand, Y. (2003). Contemporary theories and practices in education. Madison, WI: Atwood Publishing.

Bolman, L. G., \& Deal, T. E. (1995). Leading with soul (3 $3^{\text {rd }}$ ed.). San Francisco: JosseyBass.

Bolman, L. G., \& Deal, T. E. (2003). Reframing organizations: Artistry, choice and leadership ( $3^{\text {rd }}$ ed.). San Francisco: Jossey-Bass.

Burns, J. M. (1978). Leadership. New York: Harper \& Row.

Cacioppo, J. T., Hawkley, L. C., Rickett, E. M., \& Masi, C. M. (2005). Sociality, spirituality, and meaning-making: Chicago health, aging, and social relations study. Review of General Psychology, 9(2), 143-155.

Conger, J. A. (1994). Spirit at work. San Francisco: Jossey-Bass.

Deacon, T. (1997). The symbolic species. London: Allen Laine. 
Journal of Curriculum and Instruction (JoCl), November 2009, Volume 3, Number 2, (Barbara B. Howard, Precious Guramatunhu-Mudiwa, and Stephen R. White)

Denhardt, R. B. (1981). In the shadow of the organization. Lawrence, KS: University Press Kansas.

Dent, E. B., Higgins, M. E., \& Wharff, D. M. (2005). Spirituality and leadership: An empirical review of definitions, distinctions, and embedded assumptions. The Leadership Quarterly, 16(5), 625-653.

Edwards, A. C. (2003). Response to the spiritual intelligence debate: Are some conceptual distinctions needed here? The International Journal for the Psychology of Religion, 13(1), 49-52.

Emmons, R. A. (1999). The psychology of ultimate concern: Motivation and spirituality in personality. New York: Guilford Press.

Emmons, R. A. (2000a). Is spirituality an intelligence? Motivation, cognition and the psychology of ultimate concern. The International Journal for the Psychology of Religion, 10(1), 3-26.

Emmons, R. A. (2000b). Spirituality and intelligence: Problems and prospects. The International Journal for the Psychology of Religion, 10(1), 57-64.

Friedman, A. A. (2004). Beyond mediocrity: Transformational leadership within a transactional framework. International Journal of Leadership in Education, 7(3), 203-224.

Fry, L. W. (2003). Toward a theory of spiritual leadership. The Leadership Quarterly, 14(6), 693-727.

Fry, L. W., \& Cohen, M. P. (2009). Spiritual leadership as a paradigm for organizational transformation and recovery from extended work cultures. Journal of Business Ethics, 84, 265-278.

Fry, L. W., \& Slocum, J. W., Jr. (2008). Maximizing the triple bottom line through spiritual leadership. Organizational Dynamics, 37(1), 86-96.

Gardner, H. (2000). Intelligence reframed: Multiple intelligence for the $21^{\text {st }}$ century. New York: Basic Books.

Glazer, S. (1994). The heart of learning: Spirituality in education. New York: Jeremy P. Tarcher.

Greenleaf, R. K. (1977). Servant leadership: A journey into the nature of legitimate power and greatness. Mahwah, NJ: Paulist Press. 
Journal of Curriculum and Instruction (JoCl), November 2009, Volume 3, Number 2, (Barbara B. Howard, Precious Guramatunhu-Mudiwa, and Stephen R. White)

Hyde, B. (2004). The plausibility of spiritual intelligence: Spiritual experience, problem solving and neural sites. International Journal of Children's Spirituality, 9(1), 3952.

Kessler, R. (2000). The soul of education: Helping student find connection, compassion, and character at school. Alexandria, VA: Association for Supervision and Curriculum Development.

Kouzes, J. M., \& Posner, B. Z. (2002). The leadership challenge ( $3^{\text {rd }}$ ed.). San Francisco: Jossey-Bass.

Mayer, J. D. (2000). Spiritual intelligence or consciousness? The International Journal for the Psychology of Religion, 10(1), 47-56.

Miller, J. P. (2000). Education and the soul: Toward a spiritual curriculum. Albany, NY: State University of New York Press.

Miller, J. P., \& Nakagawa, Y. (2002). Nurturing our wholeness: Perspective on spirituality in education. Brandon, VT: Foundation for Educational Renewal.

Moffett, J. (1994). Spiritual awakening through education. San Francisco: Jossey-Bass.

Morgan, G. (1997). Images of organization. San Francisco: Berrett-Koehler.

Moxley, R. S. (2000). Transformational leadership and spirit. San Francisco: JosseyBass.

Neiman, A. V. (2000). Democracy and the education of the heart: Nel Noddings on spirituality and schooling. Religious Education, 95(2), 216-230.

North Carolina State Board of Education. (2006). The standards for school executives [PDF document]. Retrieved from http://www.ncpublicschools.org/docs/profdev/ guidelines/school-executives-standards/principals.pdf

North Carolina Department of Public Instruction. (2008). North Carolina school executive: Principal evaluation process. Raleigh, NC: Author.

Owens, R. G., \& Valesky, T. C. (2007). Organizational behavior in education: Adaptive leadership and school reform ( $9^{\text {th }}$ ed.). Boston, MA: Pearson Education.

Parsons, J., Fenwick, T. J., Parson, J., English, L. M., \& Wells, A. T. (2002). Spirituality of adult education and training. New York: Krieger Publishing.

Persinger, M. A. (1996). Feelings of past lives as expected perturbations within neurocognitive processes that generate the sense of self: Contributions from 
Journal of Curriculum and Instruction (JoCl), November 2009, Volume 3, Number 2, (Barbara B. Howard, Precious Guramatunhu-Mudiwa, and Stephen R. White)

limbic labiality and vectorial hemisphericity. Perceptual and Motor Skills, 83(2), 1107-1121.

Ramachandran, V. S. (1999). Phantoms in the brain: Exploring the mysteries of the human brain. London: Fourth Estate.

Rogers, J. L. (2003). Preparing spiritual leaders: One teacher takes on the challenge. About Campus, 8(5), 19-26.

Sacks, P. (1999). Generation X goes to college: An eye-opening account of teaching in postmodern America ( $3^{\text {rd }}$ ed.). Chicago, IL: Open Court.

Senge, P. M., Scharmer, C. O., Jaworski, J., \& Flowers, B. S. (2004). Presence: An exploration of profound change in people, organizations, and society. New York: Doubleday.

Sergiovanni, T. J. (1992). Moral leadership: Getting to the heart of school improvement. San Francisco: Jossey-Bass.

Sergiovanni, T. J. (2005). Strengthening the heartbeat: Leading and learning together in schools. San Francisco: Jossey-Bass.

Sinetar, M. (2000). Spiritual intelligence: What we can learn from the early awakening child. Maryknoll, NY: Orbis Press.

Singer, W. (1999). Neurobiology: Striving for coherence. Nature, 397, 391-393.

Singer, W. \& Gray, C. M. (1995, March). Visual feature integration and the temporal correlation hypothesis. Annual review of Neuroscience, 18, 555-586.

Starratt, R. J. (1996). Transforming educational leadership: Meaning, community, and experience. New York: McGraw-Hill.

Thompson, C. M. (2004). The congruent life: Following the inward path of fulfilling work and inspired leadership. San Francisco: Jossey-Bass.

Tisdell, E. J. (2003). Exploring spirituality and culture in adult and higher education. San Francisco: Jossey-Bass.

Vaughan, F. (2002). What is spiritual intelligence? Journal of Humanistic Psychology, 42(2), 16-33.

Wolman, R. W. (2001). Thinking with your soul: Spiritual intelligence and why it matters. New York: Harmony Books. 
Journal of Curriculum and Instruction (JoCl), November 2009, Volume 3, Number 2, (Barbara B. Howard, Precious Guramatunhu-Mudiwa, and Stephen R. White)

Yang, K. (2006). The spiritual intelligence of nurses in Taiwan. Journal of Nursing Research, 14(1), 24-35.

Yukl, G. A. (1994). Leadership in organizations ( $2^{\text {nd }}$ ed.). Englewood Cliffs, NJ: PrenticeHall.

Zohar, D. (2005). Spiritually intelligent leadership. Leader to Leader, 38, 45-51.

Zohar, D., \& Marshall, I. (2001). SQ: Spiritual intelligence the ultimate intelligence. London: Bloomsbury Publishing.

\section{About the Authors:}
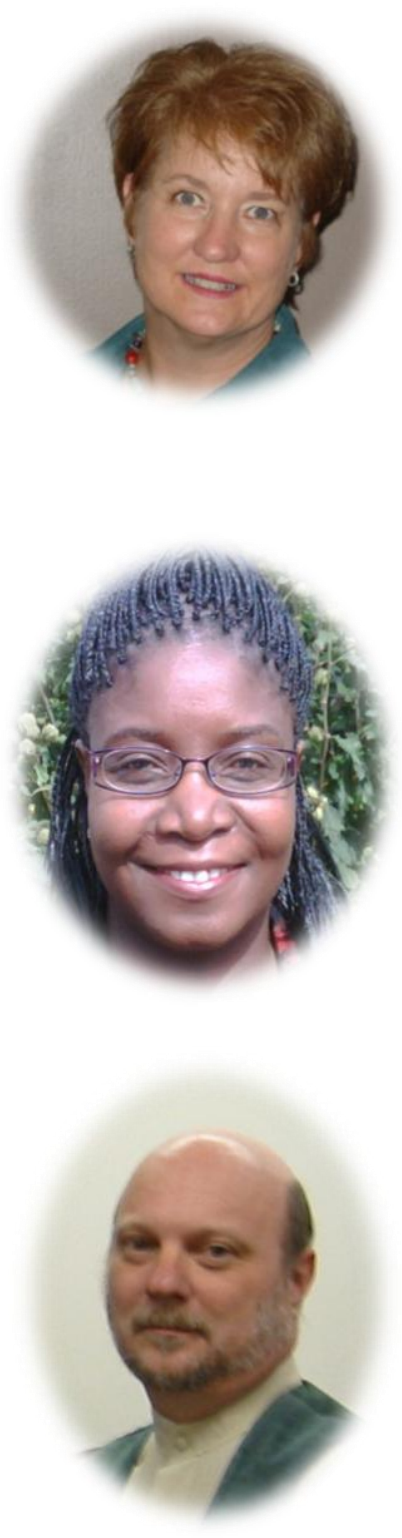

Dr. Barbara B. Howard is an Assistant Professor and Program Coordinator for School Administration in the Department of Leadership and Educational Studies in the Reich College of Education, Appalachian State University, Boone, North Carolina. Her K-12 experience includes classroom teaching as well as school and district level administration. As a Project Director for SERVE, the Regional Education Laboratory for the Southeastern United States, she conducted research and development in the field of personnel evaluation and educational leadership. She served as Task Force Chair for the revision of the Personnel Evaluation Standards, $2^{\text {nd }} \mathrm{Ed}$. (2008) issued by the Joint Committee on Standards for Educational Evaluation. She is an Associate Member of the Joint Committee for Standards in Educational Evaluation and current President of the Consortium for Research on Educational Accountability and Teacher Evaluation (CREATE). Contact email: howardbb@appstate.edu.

Dr. Precious Guramatunhu-Mudiwa is an Assistant Professor in the Reich College of Education at Appalachian State University. She teaches courses in School Administration and Higher Education Administration. Her research interests focus on leadership and governance issues in higher education with an emphasis on women as leaders. Recently she has taken an interest in exploring similarities and differences in gender equity in the governance of higher education between the United States and the Southern African Development Community (SADC) Region. Contact email: mudiwap@appstate.edu.

Dr. Stephen R. White's research on global education, spiritual intelligence, learning theory, adult education and organizational leadership theory has been published in various international and national forums. Appalachian State University's College of Education has recognized him as a Scholar of Distinction. Contact email: whitesr@boone.net. 